TITLE:

\title{
Phenolic compounds from leaves of Casimiroa edulis showed adipogenesis activity.
}

\section{$\operatorname{AUTHOR}(\mathrm{S}):$}

Nagai, Hiroyuki; Tanaka, Toshiyuki; Goto, Tsuyoshi; Kusudo, Tatsuya; Takahashi, Nobuyuki; Kawada, Teruo

\section{CITATION:}

Nagai, Hiroyuki ...[et al]. Phenolic compounds from leaves of Casimiroa edulis showed adipogenesis activity.. Bioscience, biotechnology, and biochemistry 2014, 78(2): 296-300

\section{ISSUE DATE:}

2014-04-23

URL:

http://hdl.handle.net/2433/198770

\section{RIGHT:}

This is an Accepted Manuscript of an article published by Taylor \& Francis in [Bioscience, Biotechnology, and Biochemistry] on [23 Apr 2014], available online: http://www.tandfonline.com/10.1080/09168451.2014.877821.; この論 文は出版社版でありません。引用の際には出版社版をご確認ざ利用ください。;This is not the published version. Please cite only the published version. 
1 Running Title: Phenolic Compounds Showed Adipogenesis Activity

2

3

4

Phenolic Compounds from Leaves of Casimiroa edulis Showed Adipogenesis Activity

Hiroyuki NAGAI, ${ }^{1,2, \uparrow}$ Toshiyuki TANAKA,${ }^{3}$ Tsuyoshi Goto, ${ }^{1}$ Tatsuya Kusudo, ${ }^{1}$

Nobuyuki TAKAHASHI, ${ }^{1}$ and Teruo KAWADA ${ }^{1}$

${ }^{1}$ Laboratory of Molecular Function of Food, Division of Food Science and

Biotechnology, Graduate School of Agriculture, Kyoto University, Uji, Kyoto 611-0011, Japan

${ }^{2}$ Gifu Prefectural Research Institute for Health and Environmental Science, 1-1 Naka-Fudougaoka, Kakamigahara 504-0838, Japan

${ }^{3}$ Laboratory of Drug Resources, Pharmaceutical Sciences, Gifu Pharmaceutical University, 1-25-4 Daigaku-nishi, Gifu 501-1196, Japan

Received August 5, 2013; Accepted October 8, 2013

$\uparrow$ To whom correspondence should be addressed. Tel: +81-58-380-2100;

FAX:+81-58-371-5016; E-mail:nagai-hiroyuki@ pref.gifu.lg.jp

Abbreviations: LC/MS, liquid chromatography mass spectrometry; PPAR, peroxisome proliferator-activated receptor; FA, fatty acid

Casimiroa edulis is known as cochitzapotl, and it belongs a species of tropical fruiting tree in the family Rutaceae, native to eastern Mexico and Central America south to Costa Rica. In this study, we isolated two furocoumarins and two polymethoxyflavones from leaves of Casimiroa edulis and evaluated the functions of glucose and lipid metabolism activity with 3T3-L1 adipocytes. We discovered that the addition of furocoumarins increased glucose uptake and lipid accumulation in 3T3-L1 
1 adipocyte. These results suggest that furocoumarin compounds can be used as

2 functional food-derived compounds, to regulate adipocyte functioning for the

3 management of metabolic syndrome, which is associated with dysfunctions of glucose 4 and lipid metabolism.

5

6 Key words: liquid chromatography/mass spectrometry (LC-MS); adipocyte; 7 peroxisome proliferator-activated receptor (PPAR); fatty acid (FA) syntheses; phenolic 8 compounds

Casimiroa edulis is a species of tropical fruiting tree. Zapotin in Casimiroa edulis has been found to induce both cell differentiation and apoptosis in cultured human promyelocytic leukemia HL-60 cells. ${ }^{1)}$ This compound inhibits 12-O-tetradecanoylphorbol 13-acetate (TPA)-induced ornithine decarboxylase (ODC) activity in human bladder carcinoma cells (T24 cells) and TPA-induced nuclear factor-kappa B (NF- $\kappa \mathrm{B})$ activity in human hepatocellular liver carcinoma cells (HepG2 cells). ${ }^{2)}$ The data suggest that zapotin deserves further investigation as a potential cancer suppressive agent. Crude plant extracts of seeds and of leaves of Casimiroa edulis have been found to affect blood pressure, cardiac activity, ${ }^{3-5)}$ and aortic muscular tone, ${ }^{6)}$ and to possess anticonvulsant activity, ${ }^{7,8)}$ but previous study has focused mainly on seed components and leaf components that were not studied well.

Adipocytes play a major role in the maintenance of energy balance. The amount of glucose uptake into the adipocytes is significant in the maintenance of serum glucose levels, because adipocyte-specific knock-out of an insulin-dependent glucose transporter (glut4) results in diabetic symptoms. ${ }^{9)}$ Lipid synthesis (lipogenesis) is also a 
1 vital function of adipocytes. In vivo studies have suggested that adipose tissue is

2 responsible for more than $50 \%$ of fatty acid synthesis in mammals. ${ }^{10)}$ Fatty acid (FA)

3 synthesis is a cytosolic process utilizing acetyl CoA as precursor. It is generally

4 accepted that fatty acid is synthesized from various substrates (glucose, pyruvate, lactate and acetate). ${ }^{11)}$ It is indispensable for the management of adipocyte functions to evaluate complicated metabolisms, including lipogenesis and glucose uptake.

In this study, we tried to isolate phenolic compounds from Casimiroa edulis

8 leaves, and investigated other effect, adipogenesis, including glucose uptake, fatty acid synthesis activity, and lipid accumulation with 3T3-L1 adipocytes. PPAR $\gamma$ synthesized ligand, pioglitazone, was used as positive control, since PPAR $\gamma$ is abundantly expressed in 3T3-L1 adipocytes and plays a central role in metabolism and differentiation. ${ }^{12)}$ Pioglitazone, a major insulin sensitizer, promotes preadipocyte metabolism including glucose uptake and FA synthesis through PPAR $\gamma$ activation ${ }^{13)}$ and is widely used in the treatment of type 2 diabetes.

\section{Materials and Methods}

Leaves of Casimiroa edulis were collected at the Botanical Garden of Nippon

Shinyaku Co., Kyoto, Japan. The voucher specimen was deposited at Gifu Pharmaceutical University. ${ }^{13} \mathrm{C}_{6}$ glucose and pioglitazone was purchased from Sigma (St. Louis, MO). $\left[1,2,3,4,5,6,7,8,9,10,11,12,13,14,15,16-{ }^{13} \mathrm{C}\right]$ palmitic acid was from Watari (Tokyo). Unless otherwise indicated, all chemicals were purchased from Nacalai Tesque (Kyoto, Japan) or Wako Pure Chemicals (Osaka, Japan) and were of guaranteed reagent grade or tissue culture grade. 
General experimental procedures. ${ }^{1} \mathrm{H}$ - and ${ }^{13} \mathrm{C}$-NMR spectra were recorded on an EX400 $\left({ }^{1} \mathrm{H}\right.$ at $400 \mathrm{MHz}$ and ${ }^{13} \mathrm{C}$ at $\left.100 \mathrm{MHz}, \mathrm{JEOL}\right)$ spectrometer. Chemical shifts appeared as $\delta$ values with trimethylsilane (TMS) as internal reference. Peak multiplicities were quoted in Hz. EI-MS was recorded on a JMSDX-300 (JOEL) spectrometer. Kiesel gel 60 (60-230 mesh, Merck, Japan) and Fuji Silysia Chemical Chromatorex ODS (100-200 mesh) were used for column chromatography. Kiesel-gel $60 \mathrm{~F}_{256}$ (Merck, Tokyo) at $0.25 \mathrm{~mm}$ was used for analytical and $0.5 \mathrm{~mm}$ for preparative TLC.

Extraction and isolation of compounds. Dried leaves (550 g) extracted with $\mathrm{MeOH}(1 \mathrm{~L} \mathrm{x} 5$ times) at room temperature and was evaporated in vacuo. The $\mathrm{MeOH}$ extract (52 g) obtained was chromatographed on Silica gel $(250 \mathrm{~mm} \times 30 \mathrm{~mm})$ with a mixture of chloroform $-\mathrm{MeOH}$ by increasing the polarity from $0 \%$ to $10 \%$ methanol. The chloroform-MeOH (10:1) (3.5g) was further chromatographed on an ODS column ( $250 \mathrm{~mm} \times 20 \mathrm{~mm}$ ) eluted with $\mathrm{H}_{2} \mathrm{O}$, followed by increasing the concentration of $\mathrm{MeOH}$ to give four fractions. Fraction $2(263 \mathrm{mg}, 70 \%$ methanol) was repeatedly purified by preparative TLC ( $n$-hexane-EtOAc 1:4) to give $\mathbf{1}(5 \mathrm{mg}), \mathbf{2}(7 \mathrm{mg}), \mathbf{3}$ (12 $\mathrm{mg})$, and 4 (10 mg).

8-(3'-Hydroxymethyl-but-2-enyloxy)-psoralen acetate (compound 1). White amorphous solid. Negative ion FABMS $[\mathrm{M}-\mathrm{H}]^{-} \mathrm{m} / 2,327 .{ }^{1} \mathrm{H} \mathrm{NMR}\left(\mathrm{CDCl}_{3}\right) \delta: 1.81(3 \mathrm{H}$, br s, H-5'), 2.04 (3H, s, acetyl-Me), $4.66(2 \mathrm{H}$, br s, H-4'), 5.09 (2H, br d, $J=7.0 \mathrm{~Hz}$, H-1'), $5.86\left(1 \mathrm{H}, \mathrm{brt} t, J=7.0 \mathrm{~Hz}, \mathrm{H}-3^{\prime}\right), 6.38(1 \mathrm{H}, \mathrm{d}, J=10.0 \mathrm{~Hz}, \mathrm{H}-4), 6.82(1 \mathrm{H}, \mathrm{d}, J=$ $2.5 \mathrm{~Hz}, \mathrm{H}-9), 7.37(1 \mathrm{H}, \mathrm{s}, \mathrm{H}-5), 7.69(1 \mathrm{H}, \mathrm{d}, J=2.5 \mathrm{~Hz}, \mathrm{H}-10), 7.77(1 \mathrm{H}, \mathrm{d}, J=10.0 \mathrm{~Hz}$, $\mathrm{H}-3):{ }^{13} \mathrm{C}$ NMR $\left(\mathrm{CDCl}_{3}\right)$ $\delta: 160.43$ (C-2), 114.83 (C-4), 144.27 (C-4), 116.54 (C-4a), 113.81 (C-5), 125.95 (C-6), 148.32 (C-7), 131.39 (C-8), 143.67 (C-8a), 106.76 (C-9), 146.76 (C-10), 69.12 (C-1'), 125.13 (C-2'), 136.57 (C-3'), 62.79 (C-4'), 21.42 (C-5'), 20.83 (acetyl-Me), 170.85 (acetyl C=O). 
8-(3'-Hydroxymethyl-but-2-enyloxy)-5-methoxypsoralen acetate (compound 2). White amorphous solid. Negative ion FABMS $[\mathrm{M}-\mathrm{H}]^{-} \mathrm{m} / z$ 357. ${ }^{1} \mathrm{H} \operatorname{NMR}\left(\mathrm{CDCl}_{3}\right) \delta$ : 1.80 (3H, s, H-5'), 2.03 (3H, s, acetyl Me), 4.18 (3H, s, C-5 OMe), 4.66 (2H, br s, H-4'), $4.91\left(2 \mathrm{H}, \mathrm{br} \mathrm{d}, J=7.0 \mathrm{~Hz}, \mathrm{H}-1^{\prime}\right), 5.86\left(1 \mathrm{H}, \mathrm{br} \mathrm{t}, J=7.0 \mathrm{~Hz}, \mathrm{H}-2^{\prime}\right), 6.28(1 \mathrm{H}, \mathrm{d}, J=10.1$ $\mathrm{Hz}, \mathrm{H}-3), 6.99(1 \mathrm{H}, \mathrm{d}, J=2.5 \mathrm{~Hz}, \mathrm{H}-9), 7.64(1 \mathrm{H}, \mathrm{d}, J=2.5 \mathrm{~Hz}, \mathrm{H}-10), 8.12(1 \mathrm{H}, \mathrm{d}, J=$ $10.1 \mathrm{~Hz}, \mathrm{H}-4) ;{ }^{13} \mathrm{C}$ NMR $\left(\mathrm{CDCl}_{3}\right) \delta: 160.42(\mathrm{C}-2), 112.91$ (C-3), 139.55 (C-4), 107.61 (C-4a), 144.26 (C-5), 114.61 (C-6), 150.57 (C-7), 136.51 (C-8), 125.63 (C-8a), 105.12 (C-9), 145.16 (C-10), 69.36 (C-1'), 125.27 (C-2'), 136.51 (C-3'), 62.78 (C-4'), 21.41 (C-5'), 20.84 (acetyl Me), 170.84 (acetyl C=O), 60.79 (3H, s, C-5 OMe).

5,6,2',3',5',6'-Hexamethoxyflavone (compound 3). White amorphous solid: exhibited spectral data $\left({ }^{1} \mathrm{H}\right.$ NMR and EIMS) comparable to published data. ${ }^{14)}$

5.6.2'-Trimethoxyflavone (compound 4). White amorphous solid: ${ }^{1} \mathrm{H}$ NMR data was comparable to published data; ${ }^{6)}{ }^{13} \mathrm{C}$ NMR $\left(\mathrm{CDCl}_{3}\right) \delta: 159.05,157.90$ (C-2, C-2'), 111.68 (C-2), 178.41 (C-4), 119.07, 119.02 (C-4a, 8), 147.82 (C-5), 149.65 (C-6), 113.33 (C-7), 151.82 (C-8a), 120.65 (C-1'), 112.96 (C-3'), 132.13 (C-4'), 120.62 (C-5'), $129.07\left(\mathrm{C}^{-6} \mathbf{6}^{\prime}\right)$

LC/MS system. The Agilent Series 1100 LC system (Agilent Technologies, Waldbronn, Germany) consisting of a G1323B control module, a G1312A quaternary pump, a G1322 degasser, a G1329A, a G1330A autosampler, a G1316A column oven, and a G1314A detector, was used. The column used was an Xbridge ${ }^{\mathrm{TM}}$ (C18 $3.5 \mu \mathrm{m}$, $2.1 \times 150 \mathrm{~mm}$, Waters, Milfold, MA). The LC pump gradient was as follows: $85 \%$ mobile phase A (water in $5 \mathrm{~mm}$ ammonium acetate) and 15\% mobile B (methanol in 5 mM ammonium acetate) from 0 to 20 min, $99 \%$ mobile phase $\mathrm{A}$ and $1 \%$ mobile phase $\mathrm{B}$ from 20 to $20.1 \mathrm{~min}$, and $85 \%$ mobile phase A and $15 \%$ mobile B from 20.1 to $35 \mathrm{~min}$. 
1 The injection volume, flow rate, and column temperature were $5 \mu \mathrm{L}, 0.2 \mathrm{~mL}$, and $40^{\circ} \mathrm{C}$,

2 respectively. MS conditions were selected ion monitoring (SIM); polarity negative; 10

3 psi nebulizer gas, $150 \mathrm{~V}$ fragment ion voltage; 3,000 V Capillary voltage, $350^{\circ} \mathrm{C}$; dwell

4 time $50 \mathrm{msec}$. Unless otherwise specified, all reagents used were of analytical grade,

5 and the water was deionized. Solvent: LC/MS grade methanol. $\left[1,2,3,4,5,6-{ }^{13} \mathrm{C}\right]$ glucose

6 and $\left[1,2,3,4,5,6,7,8,9,10,11,12,13,14,15,16-{ }^{13} \mathrm{C}\right]$ palmitic acid were detected at 185 and

$7 \quad 271, \mathrm{~m} / \mathrm{z}$ respectively. ${ }^{15)}$

8 Spectra of furocoumarins were determined in LC/MS scan mode, polarity

$9 \quad$ negative $(50-400 \mathrm{~m} / \mathrm{z})$. 6890 quadrupole gas chromatograph (GC) equipped with an Agilent 5973B mass spectrometer $(\mathrm{MS})$. The GC column was a DB-5MS+DG capillary type $(30 \mathrm{~m} \times 0.25$ mm i.d., $0.25 \mu \mathrm{m}$ film thickness; J\&W Scientific, Folsom, CA). A 1- $\mu \mathrm{L}$ extract was injected in splitless mode at an injection temperature of $250^{\circ} \mathrm{C}$. The oven temperature was programmed to increase from an initial $60^{\circ} \mathrm{C}$ (held for $1 \mathrm{~min}$ ) to $300^{\circ} \mathrm{C}$ (held for 2 $\min$ ) at a rate of $20^{\circ} \mathrm{C} / \mathrm{min}$. The temperatures of the quadrupole and ion source were 150 and $230^{\circ} \mathrm{C}$. The GC-MS system was operated in scan mode $(50-500 \mathrm{~m} / \mathrm{z})$ with the electron multiplier tune value.

Cell culture. 3T3-L1 preadipocytes, purchased from the American Type Culture Collection (Rockville, MD), were grown in DMEM-high glucose medium supplemented with $10 \%$ fetal bovine serum, $100 \mathrm{U} / \mathrm{mL}$ of penicillin, and $100 \mu \mathrm{g} / \mathrm{mL}$ streptomycin at $37^{\circ} \mathrm{C}$ in $5 \% \mathrm{CO}_{2}$ using a 12 -well plate $\left(5 \times 10^{4}\right.$ cell/well $)$. Post-confluent preadipocytes were differentiated into adipocytes by adding $10 \mu \mathrm{g} / \mathrm{mL}$ insulin, $0.1 \mu \mathrm{g} / \mathrm{mL}$ dexamethasone, and $112 \mu \mathrm{g} / \mathrm{mL}$ isobutylmethylxanthine to the medium with $5 \mu \mathrm{M}$ pioglitazone, and $5 \mu \mathrm{M}$ each test compound in DMSO, as previously described. ${ }^{12)}$ The differentiation medium was removed after 2 days and replaced with 
1 DMEM-high glucose medium containing $5 \mu \mathrm{g} / \mathrm{mL}$ insulin with TZD or the test 2 compound every 2 days. Ten days after the addition of the differentiation medium, the 3 cells were plated in culture dishes for a given experiment. After differentiation, they 4 were washed with warm PBS, and the medium was replaced with glucose-free DMEM 5 containing $4.5 \mathrm{mg} / \mathrm{mL}\left[1,2,3,4,5,6-{ }^{13} \mathrm{C}\right]$ glucose. They were incubated for a further $48 \mathrm{~h}$.

6 This was repeated twice.

7

Extract and saponification. The media were collected after incubation for specific durations and diluted with methanol. Diluents were filtered with a $0.22 \mu \mathrm{m}$ filter membrane, and were analyzed by the LC/MS system. The cells were dissolved in $5 \mathrm{~mL}$ $\mathrm{KOH} 20 \%$ (ethanol:water 4:6; v/v), and hydrolyzed for $60 \mathrm{~min}$ at $80^{\circ} \mathrm{C}$, followed by acidification with $6 \mathrm{~mL} 5 \mathrm{~N} \mathrm{HCl}$. The FAs were extracted twice with $4 \mathrm{ml}$ diethylether, dried under $\mathrm{N}_{2}$ at $40^{\circ} \mathrm{C}$, dissolved in $5 \mathrm{ml}$ methanol, and analyzed by the LC/MS system.

Oil Red $O$ staining. Cells were fixed with $10 \%$ formaldehyde/PBS and stained with Oil Red O solution (0.5\% Oil Red O-isopropyl alcohol/ $\left.\mathrm{H}_{2} \mathrm{O}(3: 2, \mathrm{v} / \mathrm{v})\right)$.

Statistical analysis. Results are expressed as mean and standard error of mean (SEM). Statistical significance of differences among groups was evaluated by Student's $t$-test. Differences were considered significant at $p<0.05$.

\section{Results and Discussion}

NMR analysis. The ${ }^{1} \mathrm{H}$ NMR of compound $\mathbf{1}$ showed the presence of two sets of 
1 coupled protons that $\delta 6.38$ and $7.77(J=10.0 \mathrm{~Hz})$ and $\delta 6.82$ and $7.69(J=2.5 \mathrm{~Hz})$.

2 The data indicated compound 1 was a furocoumarin. An aromatic singlet $(\delta 7.37)$ was

3 also observed that correlated with the C-4 signal of the coumarin skeleton in the HMBC

4 spectrum. Other HMBC correlations indicated that the furan ring was attached to C-6, 7,

$5 \quad$ like psoralen. ${ }^{1} \mathrm{H}$ and ${ }^{13} \mathrm{C}$ NMR showed the presence of two oxymethylene $\left(\delta_{\mathrm{H}} 4.66\right.$ and

$6 \quad 5.09$, and $\delta_{\mathrm{C}} 62.79$ and 69.12), a tri-substituted double bond $\left(\delta_{\mathrm{H}} 5.09 ; \delta_{\mathrm{C}} 125.13\right.$ and

7 136.57), a methyl attached to a double bond $\left(\delta_{\mathrm{H}} 1.81 ; \delta_{\mathrm{C}} 21.41\right)$, and an acetyl group $\left(\delta_{\mathrm{H}}\right.$

$82.04 ; \delta_{\mathrm{C}} 20.83$ and 170.85). In the HMBC spectrum, an oxymethylene proton was

9 correlated with C-8 of a coumarin. These data are characteristic of a prenyloxy group, in

10 which one of methyl groups had been oxidized to a hydroxyl methyl and acetylated. The

11 hydroxymethyl group was of the cis form with respect to the oxymethylene group (H-1') of the prenyl substituent on the basis of the NOESY spectrum (H-1'/H-4' and $\left.\mathrm{H}-2^{\prime} / \mathrm{H}-5^{\prime}\right)$.

Therefore, the structure was determined to be as described in Fig. 1. This compound was first isolated from leaves of Casimiroa pringlei. ${ }^{16,17)}$

The ${ }^{1} \mathrm{H}$ NMR spectrum of compound $\mathbf{2}$ was very similar to that of $\mathbf{1}$, but an aromatic proton disappeared and a methoxy group ( $\delta 4.18)$ was observed. An NOE was observed between the methoxy group and $\mathrm{H}-4$ of the coumarin skeleton. By detailed analysis of NMR by 2D methods, the structure of $\mathbf{2}$ was determined to 5-methoxylated compound of $\mathbf{1}$. A deacetylated coumarin of $\mathbf{2}$ was isolated from Casimiroa tetrameria. To the best of our knowledge, compound 2 was a new compound.

The structures of compounds $\mathbf{3}$ and $\mathbf{4}$ were determined and identified by comparison to previous data as 5,6,2',3',5',6'-hexamethoxyflavone (3) ${ }^{18)}$ and 5.6.2'-trimethoxyflavone $(4)^{14,18)}$ respectively.

Figure 2 shows spectra of furocoumarins and polymethoxyflavones. Parent ions of them as determined by NMR were obtained by LC/MS and GC/MS analysis (327, $357,402,312 \mathrm{~m} / \mathrm{z}$ ). This result confirms the NMR analysis data.

Glucose uptake and glycerol output activity. To elucidate the effects of 
1 compounds 1-4 on adipocyte functioning, we examined the insulin-dependent glucose uptake and glycerol output of differentiated 3T3-L1 adipocytes. As shown in Fig. 3A, the addition of $5 \mu \mathrm{M}$ compounds $\mathbf{1}$ and $\mathbf{2}$ enhanced the insulin-dependent uptake of glucose (1.2-1.3 fold increases as compared to control). The addition of the other compounds did not enhance insulin-dependent uptake of glucose. On the other hand, the addition of $5 \mu \mathrm{M}$ compounds 1-4 did not enhance glycerol output or lipolysis (Fig. 3B). These compounds at the concentrations used in this study did not affect cell viability (data not shown).

De novo FA synthesis activity and lipid accumulation of adipocytes. To assess the effects of compounds 1-4 on lipid methabolism in 3T3-L1 adipocytes, we analyzed de novo FA syntheses activty with compounds 1-4. Figure 3C shows new synthesis of palmitic acid in 3T3-L1 adipocytes treated with compounds 1-4 for $48 \mathrm{~h}$. The addition of pioglitazone at $(5.0 \mu \mathrm{M})$ increased the amounts of synthesized FA, by approximately 2.2-fold in the 3T3-L1 adipocytes as compared with control. The addition of $5.0 \mu \mathrm{M}$ conpounds $\mathbf{1}$ and $\mathbf{2}$ enhanced FA syntheses by approximately 1.5-fold as compared with control. Finally, to investigate the dose-dependent effects of furocoumarins on the lipid accumulation of adipocytes, we performed Oil Red $\mathrm{O}$ staining. The addition of furocoumarins increased lipid accumulation dose-dependently (Fig. 4).

Obesity and associated disorders are the major noncommunicable public health problems of the 21 st century. Studies indicate that high levels of body fat are associated with an increased risk of developing numerous adverse health conditions. ${ }^{19,20)}$ Hence, effective therapeutic approaches to obesity and obesity-induced metabolic syndrome are of wide interest. In this study, we isolated two furocoumarins and two polymethoxyflavones from leaves of Casimiroa edulis fruit and evaluated the functions of glucose and lipids methabolism activation. We found that the addition of furocoumarins (compounds 1 and 2) caused increased glucose uptake, FA synthesis, and 
1 lipid accumulation in 3T3-L1 adipocytes. Furanocoumarins are known to have

2 biological effects in humans. For example, bergamottin and dihydroxybergamottin are

3 attributable to the grapefruit juice effect, in which these furanocoumarins affect the

4 metabolism of certain drugs, ${ }^{21)}$ but the concentration of furanocoumarins used in our

5 assays had no influence on cell viability. They might lower blood glucose levels by

6 orally ingested in a meal or an ordinary drink, and this calls for further evaluation in

7 vivo.

1) Mata-Greenwood E, Ito A, Westenburg H, Cui B, Mehta RG, Kinghorn AD, and Pezzuto JM, Anticancer Res. 21, 1763-1770 (2001).

2) Maiti A, Cuendet M, Kondratyuk T, Croy VL, and Pezzuto JM, J. Med. Chem., 50, 350-355 (2007).

3) Garcia-Gonzalez M, Freer BE, and Morales MO, Rev. Biol. Trop., 42, 115-119 19 (1994).

20 4) Vidrio H and Magos GA, Planta Med., 57, 217-220 (1991).

5) Magos GA, Vidrio H, and Enriquez R, J. Ethnopharmacol., 47, 1-8 (1995).

6) Garzon-De la Mora P, Garcia-Lopez PM, Garcia-Estrada J, Navarro-Ruiz A, Villanueva-Michel T et al., J. Ethnopharmacol., 68, 275-282 (1999).

7) Navarro RA, Bastidas RBE, Garcia EJ, Garcia LP, and Garzon P, J.Ethnopharmacol., 45, 199-206 (1995).

8) Mata-Greenwood E, Ito A, Westenburg H, Cui B, Mehta RG, Kinghorn AD, and Pezzuto JM, Anticancer Res., 21, 1763-1770 ( 2001).

9) Spiegelman BM and Flier JS, Cell, 104, 531-543 (2001). 
1 10) Ingle DL, Bauman DE, and Garrigus US, J. Nutr., 102, 617-623 (1972).

2 11) Saggerson ED, Biochem. J., 142, 477-482 (1974).

3 12) Tzameli I, Fang H, Ollero M, Shi H, Hamm JK et al., J.Biol. Chem., 279, $4 \quad 36093-36102(2004)$.

5 13) Spiegelman BM, and Flier JS, Cell, 87, 377-389 (1996).

6 14) Eckard W, Munekazu I, Toshiyuki T, and Mizuo M, Phytochemistry, 29, 633-637 7 (1990).

8 15) Nagai H, Goto T, Takahashi N, Deyashiki Y, Esaka Y, and Kawada T, Biosci.

9 Biotechnol. Biochem., 75, 337-341 (2011).

10 16) Emma M, Imeida M, Fernando C, and Alfredo O, Heterocycles,755, 3057-3064 11 (2008).

12 17) Bilkis H, Horst R, Anita A, Otto S, Simon G et al., Phytochemistry, 66, 13 649-652(2005).

14 18) Ito A, Shamon LA, Yu B, Mata-Greenwood E, Lee SK et al., J. Agr. Food Chem., 46, $15 \quad 3509-3516(1998)$.

16 19) Cornier MA, Dabelea D, Hernandez TL, Lindstrom RC, Steig AJ et al., Endocr. 17 Rev., 29, 777-822 (2008).

18 20) Yach D, Stuckler D, and Brownell KD, Nat. Med., 12, 62-66 (2006). 21) Kakar SM, Paine MF, Stewart PW, and Watkins PB, Clin. Pharmacol. Ther., 75, $20 \quad 569-579(2004)$. 

were analyzed by GC/MS and LC/MS respectively. coumarins and polymethoxyflavones were determined by LC/MS. The concentrations of ${ }^{13} \mathrm{C}_{6}$-glucose and glycerol were determined by the LC/MS system at $185 \mathrm{~m} / \mathrm{z}$ $\left({ }^{13} \mathrm{C}_{6}\right.$-glucose) and $91 \mathrm{~m} / \mathrm{z}$ (glycerol) respectively. De novo synthesis of palmitic acid was monitored by analyzing $271(\mathrm{~m} / \mathrm{z})$. Lane 1, control; lane 2, pioglitazone; lanes 3-4, compounds 1 and 2; lanes 5 and 6, compounds 3 and 4 respectively. Lane 1, control; 
14 respectively. Concentrations (in $\mu \mathrm{M}$ ) at all data points is $5.0 * * p<0.05$ compared to 2 control.

3

4 Fig. 4. De Novo ${ }^{13}$ C-FA Synthesis and Lipid Accumulation of 3T3-L1 Adipocytes.

5

Adipocytes treated with pioglitazone or compounds 1,2 (furocoumarins) (1-100

$6 \mu \mathrm{M})$ were fixed with $10 \%$ formaldehyde/PBS and stained with Oil Red O solution $(0.5 \%$

7 Oil Red O-isopropyl alcohol/ $\mathrm{H}_{2} \mathrm{O} 3: 2$, v/v). Microscopy views of representative 3T3-L1

8 cells (original magnification, $\mathrm{x}$ 100). 

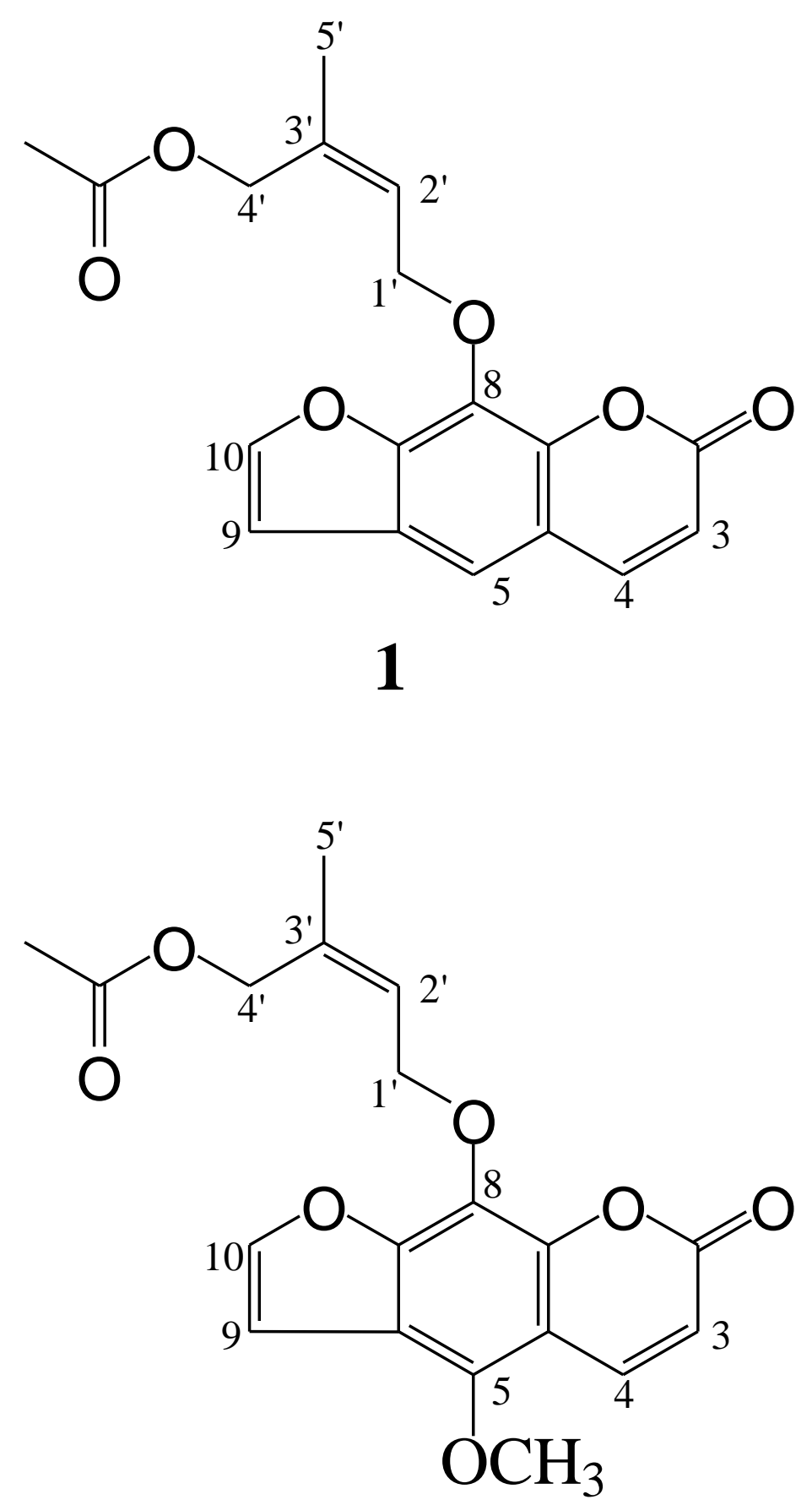

2

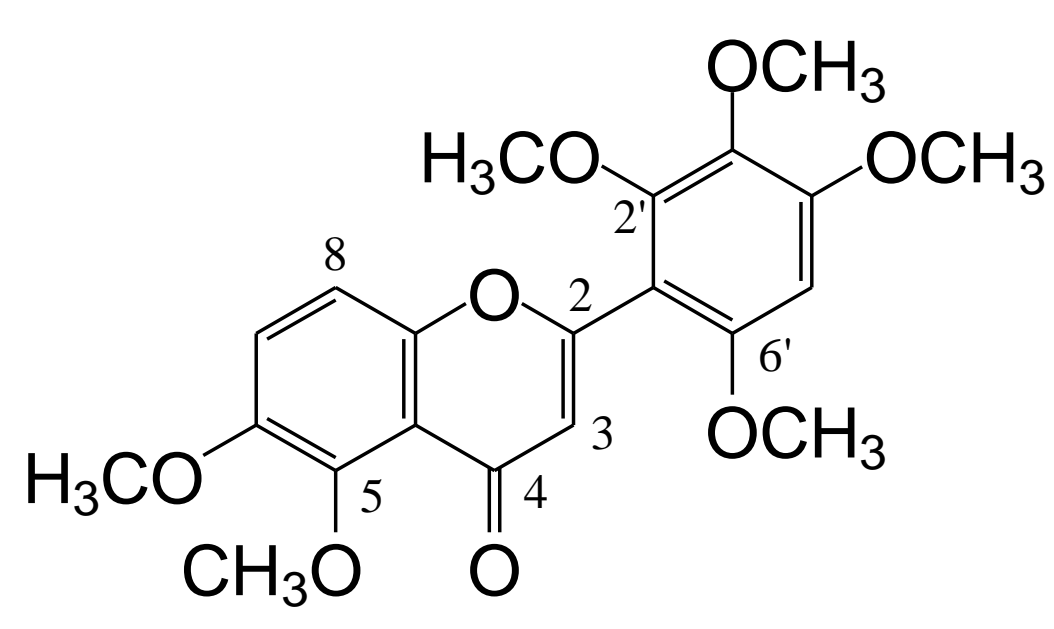

3

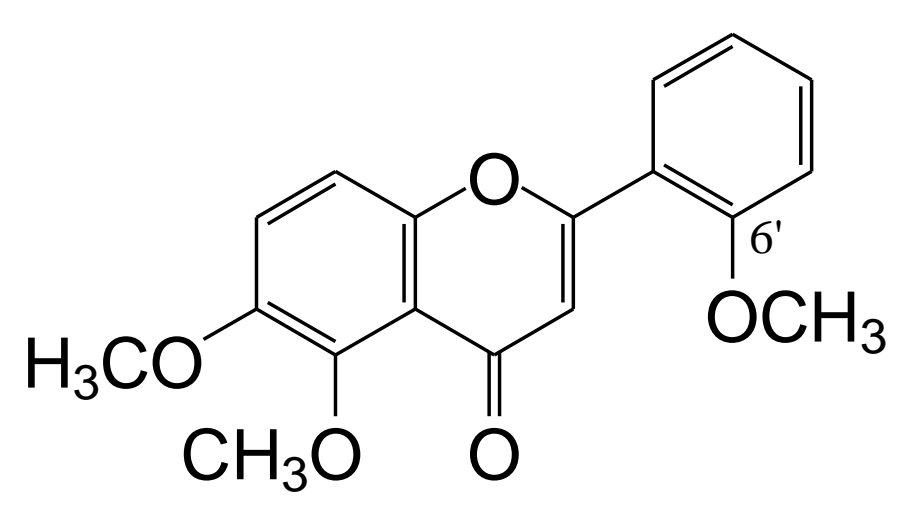

4

Figure 1, Nagai 
(3.) 京都大学
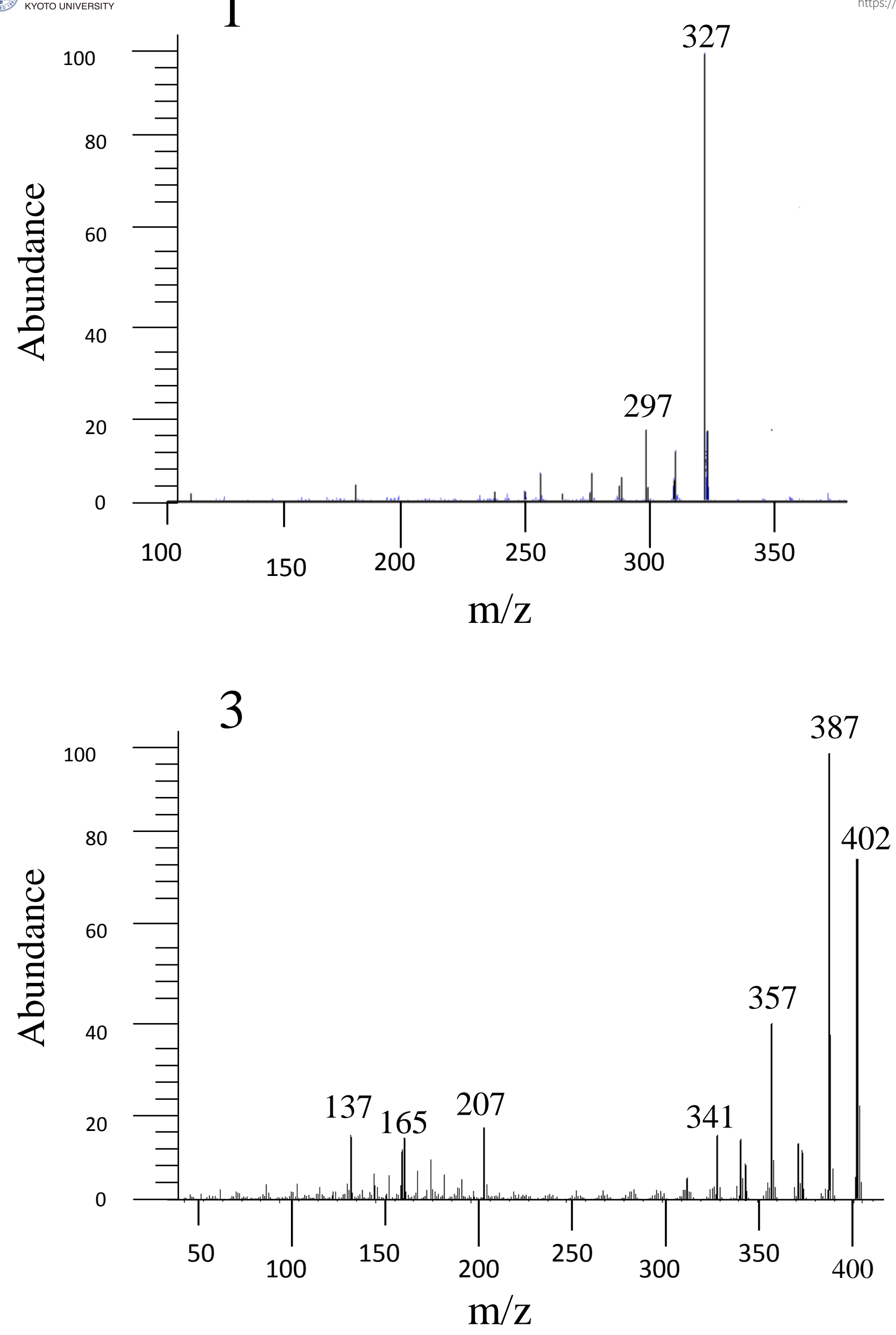
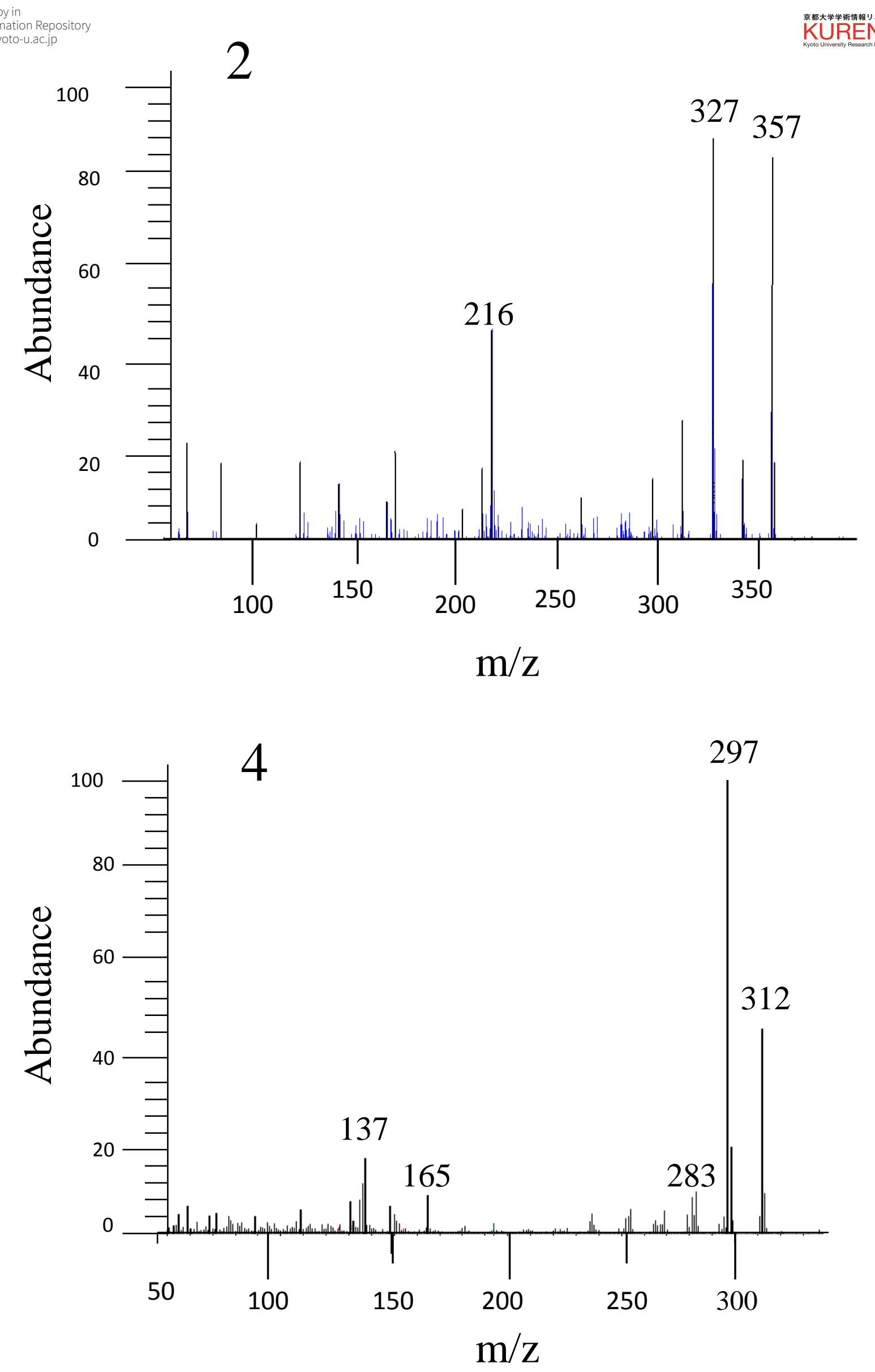

Figure 2, Nagai 
A
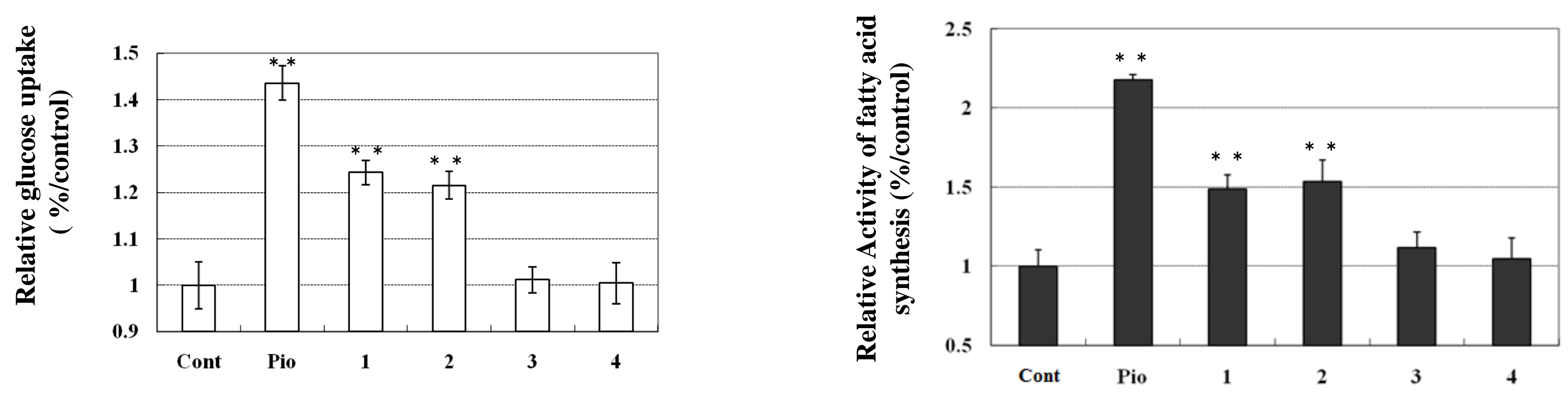

B

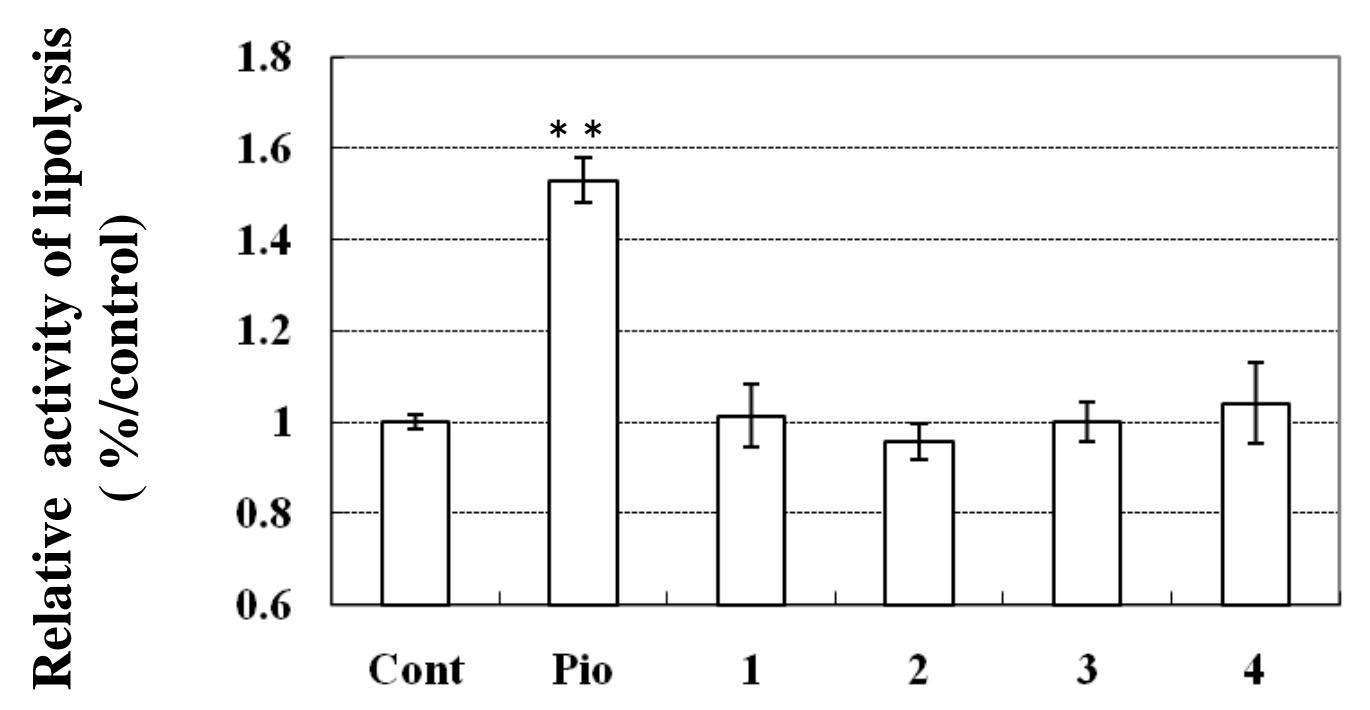

Figure 3, Nagai 


\section{Conpound 1}

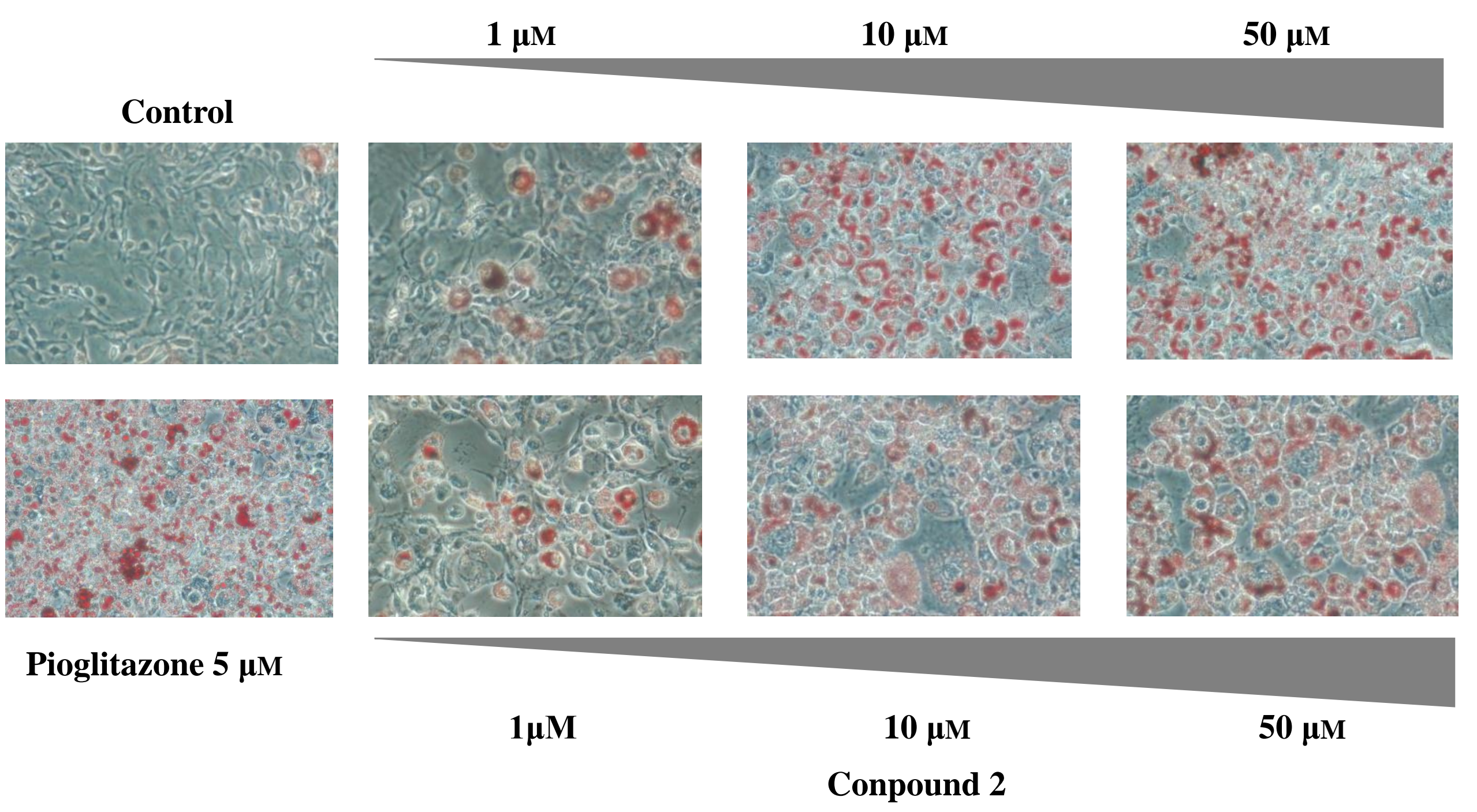

Figure 4, Nagai 